\title{
Unexpected myocardial disease in patients with life threatening arrhythmias
}

\author{
JEFFREY D HOSENPUD, JOHN H MCANULTY, NELSON R NILES \\ From the Departments of Medicine, Division of Cardiology and Pathology, Oregon Health Sciences University, \\ Portland, Oregon, USA
}

SUMMARY It is not unusual for an individual without recognisable clinical heart disease to have a life threatening arrhythmia. This report describes the results of endomyocardial biopsy in twelve patients who presented with life threatening arrhythmias and normal or near normal cardiac function. The eight men and four women (mean age 35) presented with ventricular tachycardia or fibrillation (nine cases), high grade heart block with inadequate ventricular escape (two cases), and dangerous ventricular extrasystoles (Lown grade 4, one case). In ten of the twelve patients symptoms had been present for $\leqslant 6$ months at presentation. No patient had a normal electrocardiogram. Electrophysiological testing confirmed the clinical arrhythmia in all but three patients. Endomyocardial biopsy demonstrated lymphocytic myocarditis in two patients, granulomatous myocarditis in two patients, small vessel vasculitis in one patient, and cardiomyopathic changes in six patients. In one patient the biopsy specimen was normal.

Endomyocardial biopsy is a valuable diagnostic tool in patients with unexplained life threatening arrhythmias. In this study half the patients had a treatable form of heart muscle disease.

Several studies have suggested that patients with sustained ventricular arrhythmias (tachycardia or fibrillation) and no obvious structural cardiac disease have a better prognosis than patients with the same arrhythmia associated with ischaemic, valvar, or myopathic heart disease. ${ }^{1-6}$ The possibility of occult myocardial disease in patients with otherwise unexplained arrhythmias has been considered. ${ }^{7}$ This possibility was supported by two series of patients with unexplained sustained ventricular arrhythmias who underwent endomyocardial biopsy as part of their cardiac evaluation. In both of these studies most $(90 \%)$ of the patients had abnormal myocardial histology. ${ }^{89}$ It may be that the presence of absence of myocardial pathology is an important factor in the prognosis of such patients.

In our hospital endomyocardial biopsy is performed in patients with life threatening arrhythmias and otherwise normal or near normal cardiac function to determine whether they have occult poten-

Requests for reprints to Dr Jeffrey D Hosenpud, Division of Cardiology, Oregon Health Sciences University, 3181 SW Sam Jackson Park Road, Portland, Oregon 97201, USA.

Accepted for publication 12 March 1986 tially treatable myocardial disease. The results in the first twelve patients suggest that unrecognised disease is common.

\section{Patients and methods}

From August 1983 to September 1985, 12 patients underwent endomyocardial biopsy at the Oregon Health Sciences University to investigate a life threatening arrhythmia without an obvious cardiac cause. Before biopsy a history was taken, physical examination, and haematological and biochemical screens were performed, and an electrocardiogram and chest $x$ ray were obtained. Six patients had left and right heart catheterisations (cases $1,3,7,8,10$, and 12), five patients had left heart catheterisation alone (cases $2,4,6,9$, and 11 ), and one patient had only a right heart study (case 5 ). All except patient 5 (a boy of 15) had left ventricular contrast and coronary angiography. Six patients had $M$ mode and cross sectional echocardiographic examinations.

Eleven of the 12 patients had electrophysiological testing. A tripolar electrode was positioned across the tricuspid valve to record a His potential. A hexapolar electrode was positioned at the right ventricu- 
lar apex (and later the right ventricular outflow tract) for stimulation and recording. The proximal four electrodes were used to pace the right atrium and record a high atrial potential. Baseline $\mathrm{AH}$ and $\mathrm{HV}$ intervals were recorded, and AV conduction was evaluated by means of a single extrastimulus at two cycle lengths. Programmed ventricular stimulation was then performed at both intrinsic heart rate and a cycle length of $545 \mathrm{~ms}$ with a stimulus of $5 \mathrm{~mA}$ and a pulse width of $2 \mathrm{~ms}$. The first extrastimulus was started $400 \mathrm{~ms}$ after the last QRS complex and it was brought progressively closer by $10 \mathrm{~ms}$ intervals until the absolute refractory period was reached. It was then given $30 \mathrm{~ms}$ outside the refractory period and a second extrastimulus was introduced $300 \mathrm{~ms}$ beyond the first and brought in again by $10 \mathrm{~ms}$ intervals. The third and fourth extrastimuli were used in a similar manner. The end point of the study was either the development of a sustained ventricular arrhythmia or completion of the protocol.
Endomyocardial biopsy was performed via the right internal jugular vein by standard techniques. ${ }^{10}$ Between three and seven biopsy specimens were obtained from each patient. Specimens were fixed in formalin, mounted in paraffin wax, and stained by standard light microscopy tissue stains (haematoxylin and eosin, Mason's trichrome, periodic acid Schiff, Congo red, Jone's reticulin). Other special stains were used when necessary. Specimens were interpreted independently by two experienced observers.

\section{Results}

Table 1 summarises clinical findings in the 12 patients (eight men and four women, mean age 35 years, range 15-64 years). The clinical arrhythmia was ventricular tachycardia or fibrillation in nine patients, dangerous ventricular extrasystoles (triplets, multiform) in one patient, and high degree

Table 1 Clinical characteristics and the results of electrophysiological testing

\begin{tabular}{|c|c|c|c|c|c|}
\hline Case no & Age/sex & $\begin{array}{l}\text { Presenting } \\
\text { symptoms }\end{array}$ & Clinical rhythm & $\begin{array}{l}\text { Symptom duration } \\
\text { (mnth) }\end{array}$ & EPS results \\
\hline $\begin{array}{l}1 \\
2 \\
3 \\
4 \\
5 \\
6 \\
7 \\
8 \\
9\end{array}$ & $\begin{array}{l}28 / M \\
35 / M \\
42 / M \\
44 / M \\
15 / M \\
64 / M \\
26 / M \\
48 / F \\
30 / F\end{array}$ & $\begin{array}{l}\text { SD, CHF } \\
\text { SD } \\
\text { CHF } \\
\text { Fatigue } \\
\text { Palpitation } \\
\text { SD } \\
\text { Syncope } \\
\text { Near syncope } \\
\text { Syncope }\end{array}$ & $\begin{array}{l}\text { VT, SB } \\
\text { VF } \\
\text { CHB } \\
\text { 2AVB } \\
\text { VT } \\
\text { VF } \\
\text { VT } \\
\text { VT } \\
\text { VT (torsades de } \\
\text { pointes) }\end{array}$ & $\begin{array}{r}0 \\
1 \\
3 \\
0 \\
42 \\
1 \\
36 \\
0 \\
0\end{array}$ & $\begin{array}{l}\text { NSVT, prolonged HV } \\
\text { VT } \\
\text { - } \\
\text { SEB, prolonged AH } \\
\text { NSVT } \\
\text { VT, prolonged HV } \\
\text { VT, DAVP } \\
\text { VT } \\
\text { Normal }\end{array}$ \\
\hline $\begin{array}{l}10 \\
11 \\
12\end{array}$ & $\begin{array}{l}29 / \mathrm{M} \\
44 / \mathrm{F} \\
19 / \mathrm{F}\end{array}$ & $\begin{array}{l}\text { Palpitation } \\
\text { Palpitation } \\
\text { SD }\end{array}$ & $\begin{array}{l}\text { PVCs (Lown 4) } \\
\text { NSVT } \\
\text { VT }\end{array}$ & $\begin{array}{l}3 \\
6 \\
0\end{array}$ & $\begin{array}{l}\text { NSVT } \\
\text { RVR } \\
\text { VT }\end{array}$ \\
\hline
\end{tabular}

SD, sudden death; CHF, congestive heart failure; VT, ventricular tachycardia; SB, sinus bradycardia; CHB, complete heart block 2AVB, second degree atrioventricular block; VF, ventricular fibrillation; PVCs, premature ventricular contractions; NSVT, non-sustained ventricular tachycardia; RVR, repetitive ventricular response; DAVP, dual atrioventricular nodal pathways; EPS, electrophysiological study; SEB, sinus exit block.

Table 2 Haemodynamic, angiographic, and biopsy data

\begin{tabular}{|c|c|c|c|c|c|}
\hline Case no & $L V E D P(m m H g)$ & $C I\left(I / \min / m^{2}\right)$ & $E D V I\left(\mathrm{ml} / \mathrm{m}^{2}\right)$ & $E F$ & Biopsy findings \\
\hline $\begin{array}{l}1 \\
2 \\
3 \\
4 \\
5 \\
6 \dagger \\
7 \ddagger \\
8 \\
9 \\
10 \\
11 \\
12\end{array}$ & $\begin{array}{l}10 \\
18 \\
20 \\
12 \\
9 \star \\
13 \\
10 \\
5 \\
5 \\
6 \\
18 \\
8\end{array}$ & $\begin{array}{l}\frac{3 \cdot 8}{2 \cdot 8} \\
\frac{-1}{2 \cdot 9} \\
\frac{-1}{-} \\
\frac{-}{3 \cdot 6} \\
-\end{array}$ & $\begin{array}{r}94 \\
91 \\
151 \\
102 \\
- \\
- \\
178 \\
131 \\
52 \\
109 \\
100 \\
148\end{array}$ & $\begin{array}{l}0.76 \\
0.64 \\
0.55 \\
0.49 \\
0.53 \\
0.60 \\
0.44 \\
0.55 \\
0.46 \\
0.73 \\
0.73\end{array}$ & $\begin{array}{l}\text { Vasculitis } \\
\text { Granulomatous myocarditis } \\
\text { Cardiomyopathy } \\
\text { Granulomatous myocarditis } \\
\text { Cardiomyopathy } \\
\text { Myocarditis } \\
\text { Cardiomyopathy } \\
\text { Myocarditis } \\
\text { Cardiomyopathy } \\
\text { Cardiomyopathy } \\
\text { Normal } \\
\text { Cardiomyopathy }\end{array}$ \\
\hline
\end{tabular}

LVEDP, left ventricular end diastolic pressure; CI, cardiac index; EDVI, end diastolic volume index; EF, ejection fraction.

*LVEDP not obtained; value represents pulmonary wedge pressure.

$\lceil 40 \%$ stenosis of left anterior descending coronary artery.

$\ddagger$ Mitral valve prolapse. 
atrioventricular heart block with inadequate ventricular escape in two patients. Nine patients had had symptoms for $<3$ months. Electrocardiograms (not listed in table 1) demonstrated atrioventricular block in two patients (cases 3 and 4), intraventricular conduction abnormalities in four patients (cases $1,2,6$, and 7), non-specific ST-T wave changes in four patients (cases $7,8,9$, and 10), sinus bradycardia with intermittent junctional rhythm in one patient (case 12), and frequent ventricular extrasystoles in two patients (cases 5 and 11). Electrophysiological testing confirmed the clinical rhythm in eight of the 11 patients tested. In one (case 10) it suggested a more serious rhythm disturbance and in cases 9 and 11 no abnormalities could be elicited despite clinical ventricular tachycardia (torsades de pointes) in case 9.

Table 2 shows the left ventricular filling pressures, cardiac outputs, and angiographic and biopsy findings. All but four patients had normal filling pressures. Patient 3 underwent catheterisation after being in complete heart block for $>3$ months (assessed by symptoms), shortly after pacemaker placement. End diastolic volumes were measured in 10 patients and were normal in eight. Left ventricular ejection fraction was normal in eight of the 11 patients in whom it was measured and near normal in the remaining three. Left ventriculography was not performed in patient 5 , but echocardiography showed normal left ventricular chamber size and wall motion. Valve disease was excluded in 11 patients, and one had mitral valve prolapse. There was no evidence of obstructive coronary disease in the 11 patients in whom coronary angiography was performed.

Histological findings were abnormal in the endomyocardial biopsy specimens from 11 of the 12 patients. In two patients (cases 6 and 8 ) the number of interstitial lymphocytes was increased and there was necrosis or myocyte degeneration. These cases satisfied the criteria suggested by Edwards $e t a^{11}$ for the diagnosis of chronic lymphocytic myocarditis. Figure 1 is a biopsy specimen from patient 8, which shows an increase in interstitial round cells infiltrating the myocardium and minimal fibrosis.

Two patients (cases 2 and 4) had findings consistent with granulomatous myocarditis with granulomas, giant cells, and caseating necrosis. Special stains and cultures did not demonstrate an infectious organism. Neither patient had evidence of the involvement of other organs including the lung, lymph nodes, or skin. Figure 2 shows a biopsy specimen from patient 4 in which there is a giant cell and granuloma surrounded by normal myocardium.

The biopsy specimen from patient 1 showed findings consistent with a small vessel (venule) vas- culitis (Fig. 3). This patient had a normal erythrocyte sedimentation rate and no other evidence of systemic vasculitis.

Of the remaining seven patients, six had hypertrophy, interstitial fibrosis, and nuclear atypia consistent with cardiomyopathy. ${ }^{12-14}$ Myocardial tissue from patient 3 showed extensive interstitital fibrosis and variation in cell size consistent with hypertrophy (Fig. 4).

\section{Discussion}

There is evidence that patients with ventricular arrhythmias in the absence of overt heart disease have a good prognosis. ${ }^{1-6}$ Nevertheless, $5-10 \%$ of these patients, many of whom are young, suffer sudden cardiac death. ${ }^{35}$ Kennedy et al demonstrated cardiac dysfunction in patients with unexplained ventricular extrasystoles, ${ }^{7}$ which suggests the presence of covert myocardial disease in such cases. As endomyocardial biopsy has become more widely used, histological evidence to support this premise has grown. ${ }^{89}$ Many of the patients in these two studies $^{89}$ had treatable disease (myocarditis), and five of the 12 patients in our study had had some form of myocardial inflammation.

A study by Mason et al that demonstrated lymphocytic myocarditis by endomyocardial biopsy in a group of patients who on clinical grounds were believed to have idiopathic dilated cardiomyopathy ${ }^{15}$ has prompted several other uncontrolled studies that not only established the histopathology findings in such cases, but also showed an improvement in cardiac function with immunosuppresive treatment. ${ }^{1116-19}$ In general only patients with severe left ventricular dysfunction were treated. The importance of this histological finding in the presence of ventricular arrhythmias or conduction disease alone without left ventricular dysfunction is unclear.

Myocardial granulomas and giant cells in the absence of infecting organisms have been reported in cases of sarcoidosis, ${ }^{20} 21$ as has the less common entity of granulomatous or giant cell myocarditis. $^{22-25}$ The absence of involvement of other organs and the presence of caseating necrosis in patients 2 and 4 suggest that they have granulomatous myocarditis. To date there are fewer than 30 reported cases of granulomatous myocarditis. In all the diagnosis was established at necropsy. ${ }^{22-25}$ The outcome in such cases is poor, with $50 \%$ of patients dying suddenly. The fact that two of our 12 patients probably had this disease suggests that it may be more common than previously appreciated in patients with unexplained ventricular arrhythmias or heart block. 


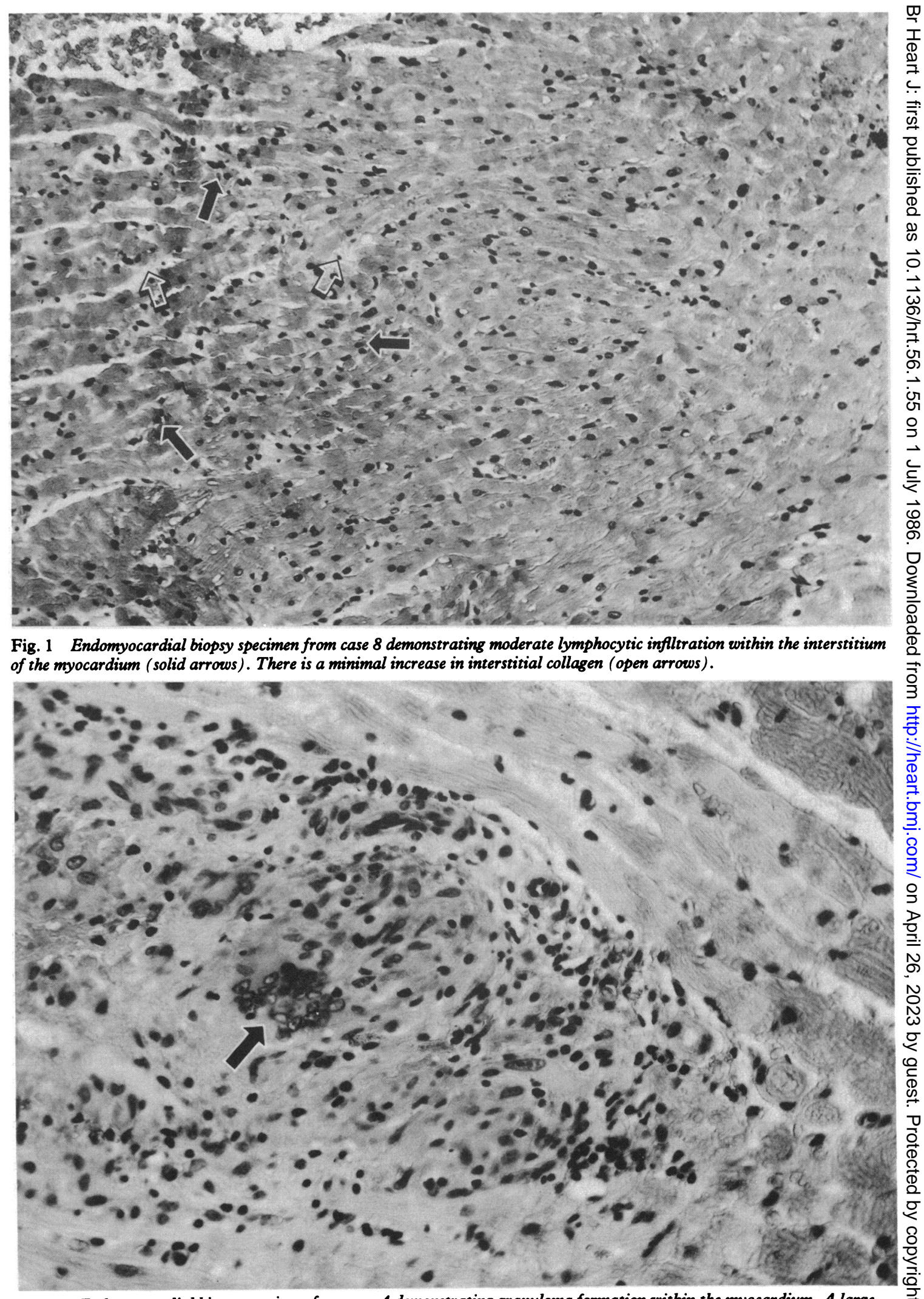

Fig. 2 Endomyocardial biopsy specimen from case 4 demonstrating granuloma formation within the myocardium. A large multinucleated giant cell is present (arrow). Special stains for acid fast organisms and fungi were negative. 


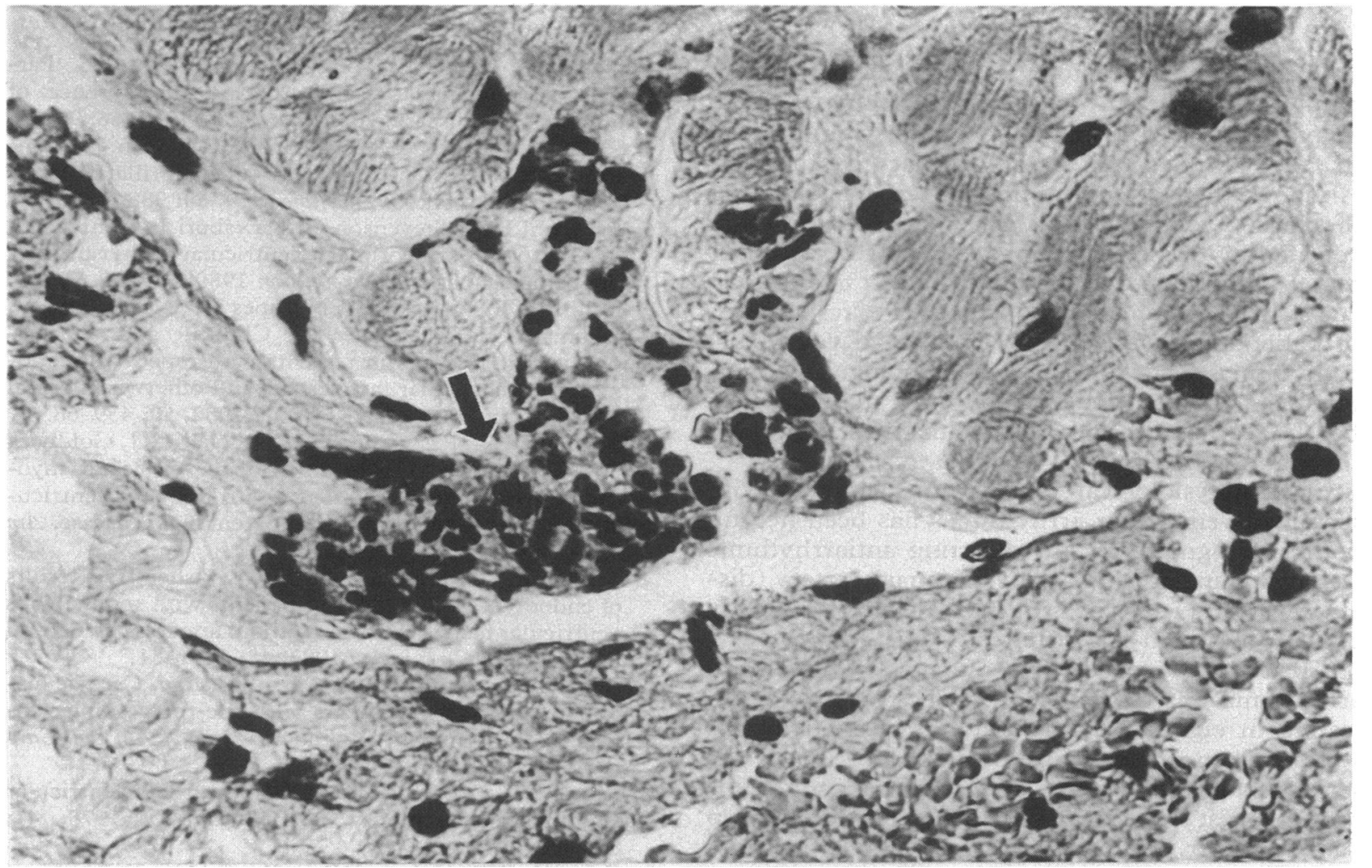

Fig. 3 Endomyocardial biopsy specimen from case 1 demonstrating an intense lymphocytic infiltrate surrounding a small venule (arrow). There was no evidence of myocardial interstitial inflammation.

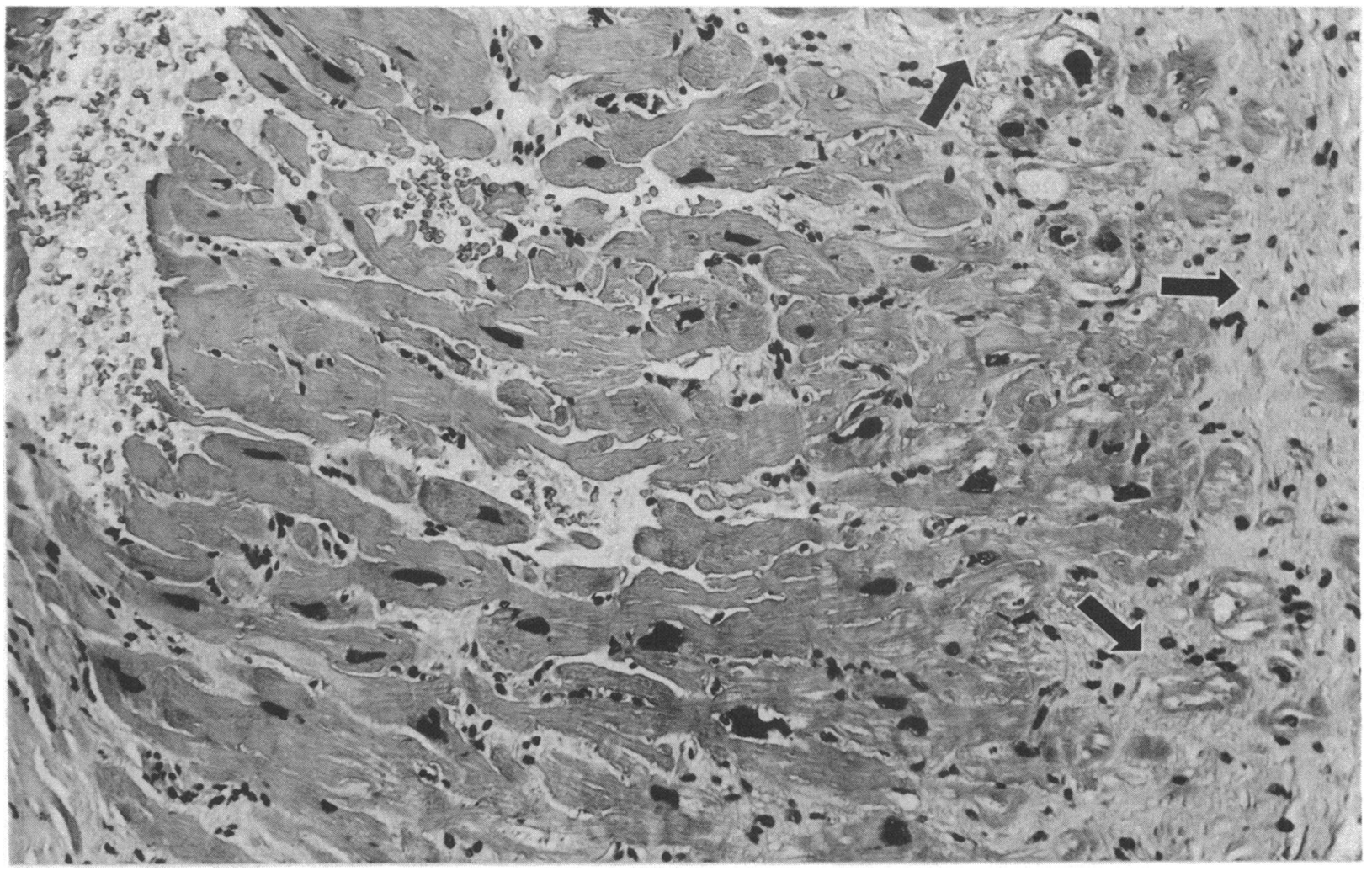

Fig. 4 Endomyocardial biopsy specimen from case 3 demonstrating findings typical of a cardiomyopathy with extensive interstitial fibrosis (arrows) and variation in the size of the myofibres and nuclei. 
Six patients had histological evidence of a cardiomyopathy with myocyte hypertrophy, nuclear atypia, and variable amounts of interstitial fibrosis, in the absence of overt cardiac dysfunction. Although the histological findings are characteristic of cardiomyopathy, they are none the less nonspecific. ${ }^{12-14}$ These findings are, however, consistent with findings reported by Strain $e t$ al and Sugrue et al who found that $56 \%$ and $75 \%$ respectively of patients with unexplained sustained ventricular arrhythmias had similar histopathological abnormalities. ${ }^{89}$ A ventricular arrhythmia may therefore be the earliest cardiovascular manifestation of a myopathic process.

Electrophysiological testing in patients with sustained ventricular arrhythmias has been helpful both in prognosis and in directing antiarrhythmic treatment in patients with coronary artery disease. ${ }^{26-28}$ Its usefulness in the absence of coronary disease, although suggested by some workers, ${ }^{29} 30$ has been less vigorously investigated. The clinical arrhythmia was reproduced by electrophysiological testing in eight of the 11 patients studied in this series and in a somewhat lower proportion in the series reported by Sugrue et al. ${ }^{9}$ These results support the test's usefulness in diagnosis. Follow up data, however, are insufficient to assess its prognostic ability. Furthermore, the specific pathology is likely to influence the usefulness of electrophysiological testing.

\section{CLINICAL IMPLICATIONS}

In this and two earlier series ${ }^{89}$ myocardial histological abnormalities were common in patients with unexplained life threatening arrhythmias and otherwise normal or near normal cardiac function. In this study most patients had symptoms for $<6$ months. Diagnostic and therapeutic approaches to these patients may be highly dependent on their specific histopathological abnormalities. Although there is currently no established treatment for myocardial disease it may be forthcoming. ${ }^{15-19} \mathrm{We}$ recommend that endomyocardial biopsy be performed in patients with unexplained life threatening arrhythmias to improve our understanding of the disease process. A better definition of this patient population will in time allow specific treatment.

\section{References}

1 Adams CW. Functional paroxysmal ventricular tachycardia. Am f Cardiol 1962; 9: 215-22.

2 Hair TE Jr, Eagen JT, Orgain ES. Paroxysmal ventricular tachycardia in the absence of demonstrable heart disease. Am f Cardiol 1962; 9: 209-14.
3 Lesch M, Lewis E, Humphries JO, Ross RS. Paroxysmal ventricular tachycardia in the absence of organic heart disease. Ann Intern Med 1967; 66: 950-9.

4 Pedersen DH, Zipes DP, Foster PR, Troup PJ. Ventricular tachycardia and ventricular fibrillation in a young population. Circulation 1979; 60: 988-97.

5 Bergdahl DM, Stevenson G, Kawabori I, Guntheroth WG. Prognosis in primary ventricular tachycardia in the pediatric patient. Circulation 1980; 62: 897-901.

6 Rahilly GT, Prystowsky EN, Zipes DP, Naccarelli GV, Jackman WH, Heger JJ. Clinical and electrophysiologic findings in patients with repetitive monomorphic ventricular tachycardia and otherwise normal electrocardiogram. Am $\mathcal{f}$ Cardiol 1982; 50: 459-68.

7 Kennedy HL, Pescarmona JE, Bouchard RJ, Goldberg RJ, Caralis DG. Objective evidence of occult myocardial dysfunction in patients with frequent ventricular ectopy without clinically apparent heart disease. $\mathrm{Am}$ Heart $\mathcal{f}$ 1982; 104: 57-65.

8 Strain JE, Grose RM, Factor SM, Fisher JD. Results of endomyocardial biopsy in patients with spontaneous ventricular tachycardia but without apparent structural heart diseae. Circulation 1983; 68: 1171-81.

9 Sugrue DD, Holmes DR, Gersh BJ, et al. Cardiac histologic findings in patients with life-threatening ventricular arrhythmias of unknown origin. $₹ \mathrm{Am}$ Coll Cardiol 1984; 4: 952-7.

10 Mason JW. Techniques for right and left ventricular endomyocardial biopsy. Am $\mathcal{F}$ Cardiol 1978; 41: 887-92.

11 Edwards WD, Holmes DR Jr, Reeder GS. Diagnosis of active lymphocytic myocarditis by endomyocardial biopsy: quantitative criteria for light microscopy. Mayo Clin Proc 1982; 57: 407-18.

12 Noda S. Histopathology of endomyocardial biopsies from patients with idiopathic cardiomyopathy: quantitative evaluation based on multivariate statistical analysis. Fpn Circ f 1980; 44: 95-116.

13 Baandrup U, Olsen EGJ. Critical analysis of endomyocardial biopsies from patients suspected of having cardiomyopathy. 1: Morphological and morphometric aspects. Br Heart $\mathcal{F} 1981$; 45: 475-86.

14 Schwarz F, Mall G, Zebe H, et al. Quantitative morphologic findings of the myocardium in idiopathic dilated cardiomyopathy. Am F Cardiol 1983; 51: 501-7.

15 Mason JW, Billingham ME, Ricci DR. Treatment of acute inflammatory myocarditis assisted by endomyocardial biopsy. Am $\mathcal{F}$ Cardiol 1980; 45: 1037-44.

16 Fenoglio JJ Jr, Ursell PC, Kellogg CF, Frusin RE, Weiss MB. Diagnosis and classification of myocarditis by endomyocardial biopsy. $N$ Engl f Med 1983; 308: 12-8.

17 O'Connell JB, Robinson JA, Henkin RE, Gunnar RM. Immunosuppressive therapy in patients with congestive cardiomyopathy and myocardial uptake of gallium-67. Circulation 1981; 64: 780-6.

18 Zee-Cheng C, Tsai CC, Palmer DC, Codd JE, Pennington DG, Williams GA. High incidence of myocarditis by endomyocardial biopsy in patients with idiopathic congestive cardiomyopathy. $\mathcal{f} \mathrm{Am}$ Coll Cardiol 1984; 3: 63-70.

19 Daly K, Richardson PJ, Olsen EGJ, et al. Acute myo- 
carditis. Role of histological and virological examination in the diagnosis and assessment of immunosuppressive treatment. Br Heart $\mathcal{F} 1984$; 51: 30-5.

20 Ghosh P, Fleming HA, Gresham GA, Stovin PGI. Myocardial sarcoidosis. Br Heart $\mathcal{f}$ 1971; 34: 769-73.

21 Silverman KJ, Hutchins GM, Bulkley BH. Cardiac sarcoid: a clinicopathologic study of 84 unselected patients with systemic sarcoidosis. Circulation 1978; 58: 1204-11.

22 Davies MJ, Pomerance A, Teare RD. Idiopathic giant cell myocarditis-a distinctive clinico-pathological entity. Br Heart $\mathcal{F}$ 1975; 37: 192-5.

23 Lindvall K, Edhag O, Erhardt LR, Sjogren A, Swahn A. Complete heart block due to granulomatous giant cell myocarditis: report of 3 cases. Eur Heart $\mathcal{F}$ 1978; 8: 349-58.

24 Tubbs S, Sheibani K, Hawk A. Giant cell myocarditis. Arch Pathol Lab Med 1980; 104: 245-6.

25 Boesen K, Hansen BF. A case of giant cell myocarditis. Acta Med Scand 1981; 210: 521-2.

26 Ruskin JN, DiMarco JP, Garan H. Out-of-hospital cardiac arrest: electrophysiologic observations and selection of long term antiarrhythmic therapy. $N$ Engl $\mathcal{F}$ Med 1980; 303: 607-13.

27 Mason JW, Winkle RA. Electrode catheter arrhythmia induction in the selection and assessment of antiarrhythmic drug therapy for recurrent ventricular tachycardia. Circulation 1978; 58: 971-85.

28 Horowitz LN, Josephson ME, Farshidi A, Spielman SR, Michelson EL, Greenspan AM. Recurrent sustained ventricular tachycardia 3 . Role of the electrophysiologic study in selection of antiarrhythmic regimens. Circulation 1978; 58: 986-97.

29 Naccarelli GV, Prystowsky EN, Jackman WM, Heger JJ, Rahilly GT, Zipes DP. Role of electrophysiologic testing in managing patients who have ventricular tachycardia unrelated to coronary artery disease. $A m \mathcal{F}$ Cardiol 1982; 50: 165-71.

30 Gulamhusein S, Naccarelli GV, Ko PT, et al. Value and limitations of clinical electrophysiologic study in assessment of patients with unexplained syncope. $A m \mathcal{F}$ Med 1982; 73: 700-5. 